\title{
Infrasellar Endoscopic Endonasal Approach for a Pituitary Adenoma Extending into the Third Ventricle, with Anterior Displacement of the Pituitary Gland
}

\author{
Georgios A. Zenonos ${ }^{1}$ Eric W. Wang ${ }^{2}$ Juan Carlos Fernandez-Miranda ${ }^{1}$ \\ ${ }^{1}$ Department of Neurosurgery, University of Pittsburgh Medical \\ Center, Pittsburgh, Pennsylvania, United States \\ 2 Department of Otorhinolaryngology, University of Pittsburgh \\ Medical Center, Pittsburgh, Pennsylvania, United States

\begin{abstract}
Address for correspondence Juan Carlos Fernandez-Miranda, MD Department of Neurosurgery, University of Pittsburgh Medical Center, 200 Lothrop Street, Suite B400, Pittsburgh, PA 15213, United States (e-mail: fernandezmirandajc@upmc.edu).
\end{abstract}

J Neurol Surg B 2018;79(suppl S2):S233-S234.

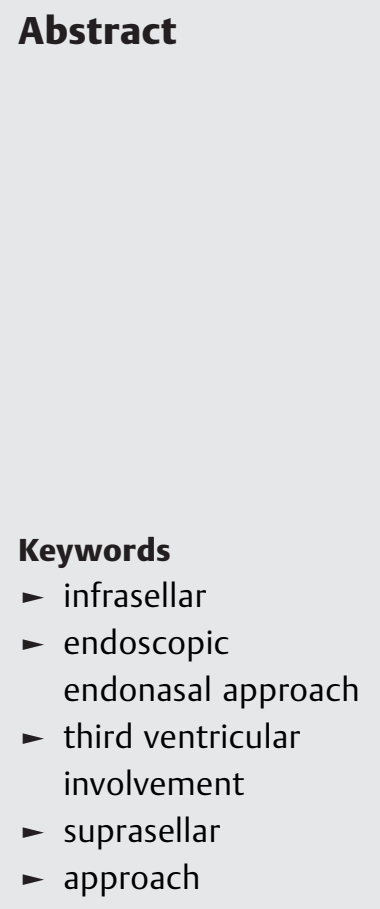

Objectives The current video presents the nuances of the infrasellar endoscopic endonasal approach for a pituitary adenoma extending into the third ventricle, with anterior displacement of the pituitary gland.

Design The video analyzes the presentation, preoperative workup and imaging, surgical steps and technical nuances of the surgery, the clinical outcome, and follow-up imaging.

Setting The patient was treated by a skull base team consisting of a neurosurgeon and an ENT surgeon at a teaching academic institution.

Participants The case refers to 73-year-old female patient who was found to have a sellar mass after failure of vision to improve with cataract surgery. She also reported a several-month history of progressive loss of vision along with daily retro-orbital headaches. The adenoma extended into the clivus as well as in the retrosellar and suprasellar regions, eroding into the floor of the third ventricle. The normal gland was displaced anteriorly.

Main Outcome Measures The main outcome measures consisted of reversal of patient symptoms (headaches and visual disturbance), recurrence-free survival based on imaging, as well as absence of any complications.

Results The patient's headaches and visual fields improved. There was no evidence of recurrence.

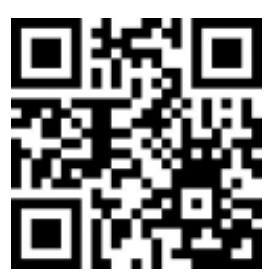

received

October 15, 2017 accepted

November 29, 2017

published online

January 16, 2018 www.thieme.com/skullbasevideos

www.thieme.com/jnlsbvideos
DOI https://doi.org/

10.1055/s-0037-1620261. ISSN 2193-6331.
๑) 2018 Georg Thieme Verlag KG
Stuttgart · New York

License terms

(c) $(1) \ominus \$$ 
Conclusion The infrasellar endoscopic endonasal approach is safe and effective for pituitary adenomas extending into the third ventricle, with anterior displacement of the pituitary gland.

The link to the video can be found at: https://youtu.be/zp_06mEyRvY.

\section{Conflict of Interest}

None.
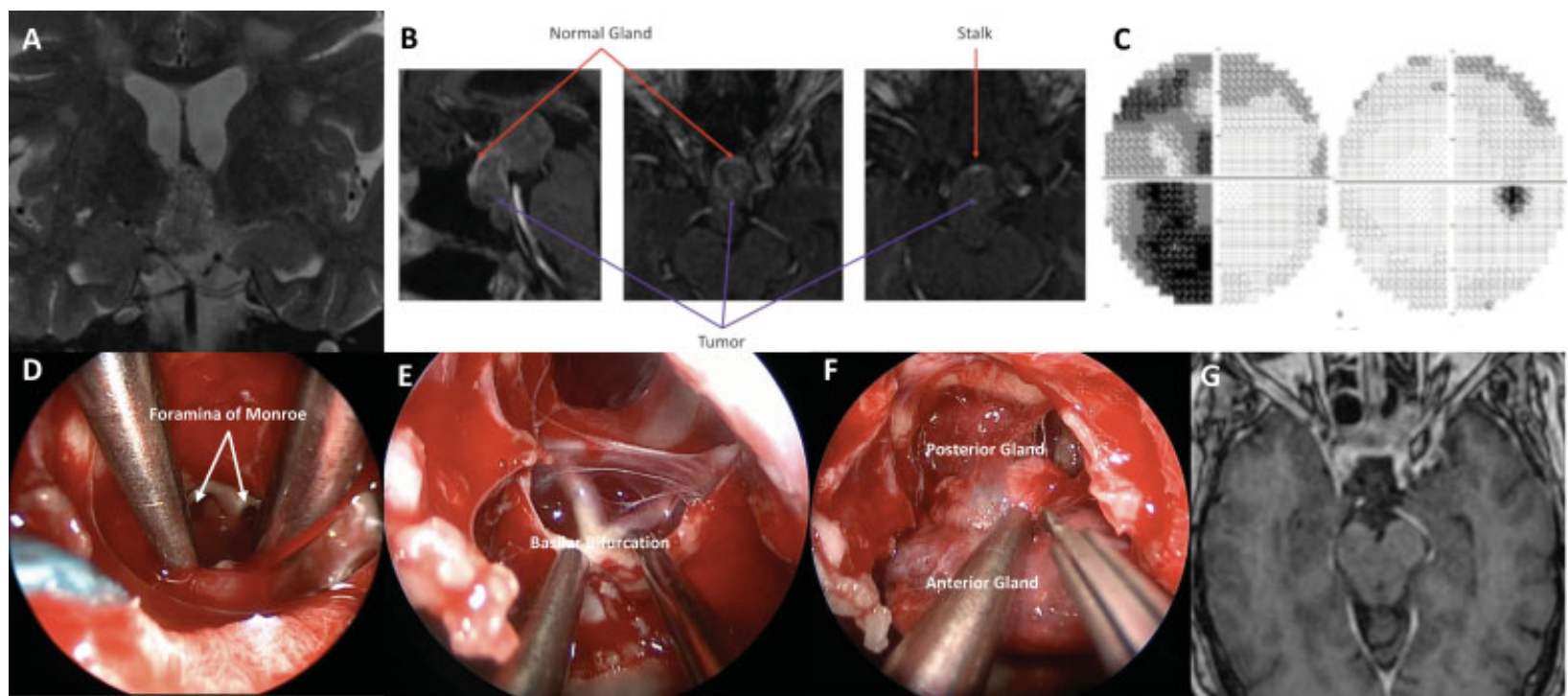

E 1 Tumor $\quad \mathbf{F}$
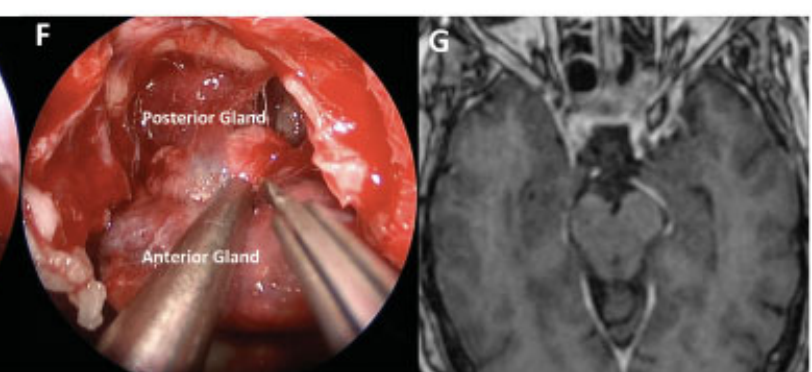

Fig. 1 (A) Preoperative T2-weighted MRI image showing invasion of the floor of the 3rd ventricle. (B) Sagittal and axial contrasted images showing anterior displacement of the normal pituitary gland. (C) Visual fields preoperatively showed left temporal hemianopia. (D) Intra-operative image showing the foramina of Monroe. (E) Resection of tumor from the retrosellar region revealed the basilar bifurcation and mammillary bodies. (F) The suprasellar region was exposed to allow for superior displacement of the pituitary gland. (G) Postoperative imaging showing complete resection of the lesion. 